\title{
Research on Teaching Quality Monitoring and Guarantee System of Secondary Colleges in Universities
}

\author{
Xiaoqing Yuan ${ }^{1, a^{*}}$, Binghe Ma ${ }^{1, b}$, Shaohui Wang ${ }^{1, c}$ and Ying Zhang ${ }^{1, d}$ \\ ${ }^{1}$ School of Mechanical Engineering, Northwestern Polytechnical University, Xi'an 710072, China \\ ayuan@nwpu.edu.cn, ${ }^{\mathrm{b}}$ mabinghe@nwpu.edu.cn, ${ }^{\mathrm{c}}$ songwsh@nwpu.edu.cn, \\ d zhangyingcdim@nwpu.edu.cn \\ * The Corresponding Author
}

Keywords: Secondary school; Teaching quality; Monitoring and guarantee system; Practice

\begin{abstract}
Teaching quality monitoring and guarantee system of secondary school is an important means of improving teaching quality of universities. The paper analyzes the questions of teaching quality monitoring and guarantee system of secondary school. Two novel teaching quality evaluation systems for teachers and practice courses are introduced separately. The teaching quality information feedback system and reward and punishment mechanism are improved. The practice shows that the new monitoring and guaranntee system can effectively promote the teaching quality improvement of the secondary school.
\end{abstract}

\section{Introduction}

The fundamental task of colleges and universities is to cultivate high-level specialized personnel with innovative spirit and practical ability. The cultivation of talents is also practiced mainly through teaching activities, and teaching work is the central work of colleges and universities, the level of teaching quality determines the quality of personnel training, and is related to the survival and development of colleges and universities[1]. Constructing a scientific teaching quality guarantee and monitoring system, strengthening the teaching quality management, continuously consolidating and improving the quality of education and teaching, these are the new tasks that colleges and universities are facing now. With the shift of school management, more and more teaching management work are undertaken by secondary school to achieve the "academy school", the teaching management task of the secondary school is transferred from the original teaching task and instruction transmitting to the more independent and flexible management and evaluation of teaching process and teaching effect. The secondary school is not only the main body of teaching work management, but also the implementer of core activities of talents training. Its management level is directly related to the teaching quality of the whole school. Although some colleges and universities have established the system of teaching quality monitoring and guarantee system at the school level[2], and there must be a large discrepancy of pertinence and flexibility in relying solely on the university's management of the teaching quality monitoring and guarantee, so it is necessary to establish a more scientific and adaptable secondary school teaching quality monitoring and guarantee system.

\section{Current Situation of Teaching Quality Monitoring and Guarantee System in Secondary Colleges}

The secondary colleges rely on the university's teaching quality monitoring system to establish the teaching quality monitoring system of their respective colleges. However, the following problems commonly exist in the running process: the unclear teaching quality monitoring objectives; the lack of systematic monitoring of the quality of education; the monitoring measures isolated from each other, which did not cover all aspects of teaching; the lack of teaching monitoring normalization; no long-term mechanism; weakening teaching quality monitoring information processing capacity; the imperfect 
continuous improvement mechanism; the lack of effective evaluation of the teaching quality of teachers; the limited methods of practical teaching quality[3]. To sum up, it can be elaborated from the following three aspects.

Lack of Subjectivity. Because the teaching quality monitoring and guarantee system of the secondary colleges follow the system of the university, in the actual implementation process, the management whose main task is organizing teaching work and accepting the university examination is still adopted because of the inertia of management. The propaganda of the college monitoring and guarantee system for teachers and students is not in place, and it did not form an effective implementation of measures, and the college leaders are not enough understanding the importance of teaching quality monitoring, and no adequate personnel and funding carry out the related work, the teaching quality monitoring is passively implemented, they did not take the college as the main body of monitoring and guarantee system to take the initiative to carry out the work.

Lack of Systematicness. The teaching quality monitoring and guarantee system in the secondary colleges pay enough attention to the teaching of theoretical courses, but take few measures to practice teaching, practical teaching cannot be effectively evaluated, which form a shackle for cultivating students' innovation ability and the ability of analyzing problems. In the monitoring of content, mostly is in the form and less connotation. At the same time, in the process of system construction, the various parts of the system are independent and lack of cohesion. There is no systematic connection with the goal of personnel training and professional training program, lack of effective information feedback mechanism and continuous improvement mechanism.

Lack of Pertinence. At present, the teaching quality monitoring and guarantee system of secondary schools are mostly based on the relevant requirements of the university. the construction targets are not sufficiently targeted in the process of contruction. They simply boil down to regulate teaching order, regulate the teaching activities of teachers and students, and ensure the smooth progress of all teaching links. This construction goal is easy to place teachers in the opposite of teaching management, and the guarantee system has less incentives, more disciplinary measures, which is easy to make teachers feel resentment, and the evaluation methods based on student evaluation makes the relationship between teachers and students becomes subtle. "Emphasis on scientific research and ignoring teaching" of job title assessment system and job evaluation methods make teachers less active in the construction of monitoring and guarantee system, to establish a practical and effective teacher teaching quality evaluation system has become a key step to improve the college teaching quality monitoring and guarantee system.

\section{Effective Ways to Improve the Teaching Quality Monitoring and Guarantee System in Secondary Colleges}

In order to perfect the teaching quality monitoring and guarantee system of the secondary colleges, we need to set clear goals for construction. In this paper, setting college of mechanical engineering of Northwestern Polytechnical University for the research object, the goal of the secondary school teaching quality monitoring and guarantee system is to standardize teaching, to ensure the continuing teaching, to ensure the effective implementation of training programs, to improve teaching quality, to update the concept of education and teaching, and combining the school teaching quality monitoring and guarantee system and society teaching quality evaluation system jointly ensures the realization of the goal of personnel training.

The procedure of the construction of teaching quality monitoring system in the secondary college: Firstly setting up a perfect teaching quality management system, and gradually forming a scientific, comprehensive and standardized quality control standard system to clarify the positioning and responsibilities of the secondary college in the process of teaching quality monitoring and clearing division of labor; Secondly, establishing and improving the information feedback system of teaching quality; Finally, we should strengthen the regulation of the teaching quality process and realize the detection of the teaching operation status. 
Establishing the Concepts of Teaching Quality Monitoring and Guarantee System. Learn from the concept of total quality management and the education concept of people-oriented, all aspects influencing teaching quality are scientificly monitored, system engineering principles is used, the "people-oriented, full participation, scientific design, operational feasibility" of the five principles are adhered to build the institutionalized, standardized and normalized teaching quality monitoring and guarantee system adapting to complete credit system. We should set the dean of college as the first responsible person of the teaching quality work responsibility system. Under the direct leadership of the vice dean of the college, the teaching office, student affairs office, each professional department and the experimental center take their responsibility of teaching quality respectively, the staff and students of the whole college should strive to survive by quality and set up the concept of quality in an all-round way.

Establishing More Actual Teaching Quality Evaluation Method of Teachers. The purpose of teaching quality evaluation is to improve teachers' development and teaching quality, and the evaluation index system should be optimized to cover teaching basic indicators, teaching process indicators and teaching effectiveness indicators. Multi-body evaluation mechanism is established with the core of students evaluation and with the supplementary of the teachers' self-evaluation, supervision group evaluation, management personnel evaluation. For the different nature of the courses, the adjustable assessment criteria is established, a comprehensive evaluation the quality of teacher is formed, and finally extension theory is used for teaching quality evaluation.

Establishing the Teaching Quality Evaluation Method for the Practice Link. We should integrate the practice link of the students, and form the four levels of the undergraduate practice system of "basic experiment, professional experiment, open experiment and innovative experiment". The basic experiment includes physical and chemistry experiment, metal processing and electronic practice, electrical and electronic experiment, material mechanics experiment and mechaninery experiment, professional experiments include various professional courses experiment, cognitive practice, production practice, course design and graduation design section. The open experiment includes the open comprehensive experiment content of the experimental centers and the professional departments. The innovative experiment includes the practice of discipline competition, innovation and entrepreneurship training plan, scientific research innovation experiment, science and technology competition and so on. According to the different nature of the practice link, the evaluation index system is adapted to the requirements of the practice link. The operation mechanism of the combination of self-evaluation, student evaluation, teaching office evaluation and the approval of the ceaching committee of the professor committee is adopted.

Improving the Teaching Quality Information Feedback System. The information feedback system is composed of the teaching inspection meeting of midterm, the summary of class adviser and various kinds of teaching bulletin. On the one hand, teaching information can be timely feedback to teachers and teaching managers and related students through teaching situation report and real-time feedback of major teaching events, so as to support and encourage advanced staff, timely treat and reform problems. On the other hand, the problems found in monitoring are feedbacked to management decision system, so that decision making departments can timely evaluate and revise teaching objectives and quality monitoring system, so as to achieve self-adjustment and improvement of teaching quality monitoring system.

Perfecting the System of Teachers' Rewards and Punishments. Scientific teaching quality reward and punishment system is a constraint mechanism for the implementation of teaching quality monitoring and guarantee system. The incentive competition mechanism is introduced and the teachers' work is evaluated to reward and punish. For teachers who have outstanding achievements in teaching assessment, their workload coefficient in teaching performance adjustment should be increased, various teaching awards are given priority to recommend when they are selected, when they promote the professional title, it is in conformity with the requirements of teaching status. For the backward teachers in the teaching work, the workload coefficient is reduced in the adjustment of teaching performance and they will be rejected in the professional title promotion. The arbitration system is introduced, and the publicity system is applied to all kinds of rewards and penalties. The person concerned and the faculty 
have the right to reflect the situation to the relevant departments. The person concerned can petition and apply for arbitration, and the management decision system will give a fair judgement.

\section{Summary}

The implementation of teaching quality monitoring system in secondary schools is of great significance to the improvement of teaching quality and the development of colleges and universities. This paper analyzes the existing problems in the teaching quality monitoring and guarantee system in the secondary colleges. Taking the school of mechanical engineering, Northwestern Polytechnical University as the research object, this article proposes new ways to improve the teaching quality monitoring and guarantee system. In particular, it puts forward a new evaluation method of teaching quality of teachers and teaching quality evaluation method in practice so as to form a strong support for the system and provides a reference for the establishment of related systems in other secondary schools.

\section{Acknowledgement}

This research was financially supported by the Teaching Reform and Research Foundation of Northwestern Polytechnical University.

\section{References}

[1] Wang Qi, Wang Yiqun, Liu Chuanqing. The construction of two level teaching quality monitoring system in applied universities. Journal of Nanjing Institute of Technology (Social Science Edition), 15 (2015) 66 69.

[2] Wang Jianian. Research on the two levels teaching supervision mechanism of new local undergraduate colleges and universities. University Education, 9 (2012) $9 \sim 16$.

[3] Liu Xiaohong, Zhao Hehua, Ma Xiaofeng. Construction and practice of teaching quality monitoring system of grade two department. Journal of Wuhan University of Science and Engineering, 22 (2009)52 55. 